\title{
Bibliometric Review: Identifying Evolving and Emergent Regulatory Trends
}

\author{
David Benton, RGN, PhD, FFNF, FRCN, FAAN
}

$\mathrm{A}$ number of studies have sought to place regulatory trends within a general systems framework to describe new and emergent trends, and issues facing nursing regulation. The nursing profession is not alone in seeking to monitor changes and trends in the regulatory environment. Such disciplines as medicine, physiotherapy, law, and accounting have also been active in this area (American Occupational Therapy Association, 2010; American Physical Therapy Association, 2011; Federation of State Medical Boards, 2014; The Financial Reporting Council, 2015; Steinecke, 2013; Terry, 2013).

In addition to profession-specific published data, more broadly based, multidisciplinary documents are available that describe trends in occupational licensing and regulation (Koumenta, Humphris, Kliener, \& Pagliero, 2014; Lester, 2014; The White House, 2015). Also, there are studies that have looked at comparing and contrasting different professional groups, how they have evolved over time, and the regulatory approaches being used (Lester, 2016).

\section{Literature Review}

Various contributions to nursing regulation literature tend to use expert opinion or, as in the case of the National Council of State Boards of Nursing $(2015,2016 \mathrm{a})$ and the Federation of State Medical Boards (2014), survey-based approaches involving members and associated stakeholders. Benton, González-Jurado, Beneit-Montesinos, and Fernandez-Fernandez (2013) utilized a thematic qualitative analysis of the published literature and a systems theory-based framework to describe the trends identified.

Recently, a number of authors have initiated studies to explore specific aspects of the evolution of nursing practice and its associated regulation. These studies (for example, Gilburt, 2016) have looked at the interface among care domains, in which positions that span the health and social care interface and assist individuals in navigating or accessing services have been explored. Gilburt's study, although comprehensive in identifying a range of new and evolving roles, concludes that the evidence base associated with these developments is far from comprehensive and that the longer-term implications are unknown. Gilburt (2016) also states that these new roles frequently face regulatory challenges, because the roles do not quite fit into the responsibilities and scope of a single regulatory body and therefore lack formal or appropriate regulation (Bienkowska-Gibbs, King, Saunders, \& Henham, 2015).

In another study, Berwick (2016) asserts that a new era of health care delivery is required as a result of tensions that have emerged from the protectionist approach of medicine and the accountability-driven approach required by payers who have taken overreporting and measurement to a level that adversely impacts care delivery and quality. Berwick (2016) contends that nine changes are needed to effect a shift away from a revenue-based model to one focused on quality. Several of Berwick's proposed changes will require a reformulation of the current model of self-regulation. Two of the suggested changes- "Give up professional prerogative when it hurts the whole" and "Protect civility" - are at the heart of team-based care and the reform of regulatory models. Other proposed changes, such as "The use of improvement science," are consistent with recent developments in the regulatory concept of continuing competence and associated processes such as revalidation. Additionally, Berwick's (2016) proposals to "Ensure complete transparency" and to "Hear the voices of the people served" both point to a renegotiation of the social contract between society and the professions. Based on these and other recent studies, it is fair to contend that the current industrial-era model of regulation has outlived its usefulness in today's digital world; as a result, the current model requires considerable revision and reform. 
The studies mentioned above are not the only ones that urge revision and reform. Other works, with application across a much wider range of regulatory areas (such as health, business, and finance) have also sought to specifically explore aspects of the role of the regulator of tomorrow. Shah, Brody, and Olson (2015) focus on two important areas that, in today's era of exponential change, they see as needing particular attention: rule making and the processes of oversight and enforcement. Although Shah and colleagues (2015) offer suggestions on how various aspects of both rule making and the associated oversight and enforcement processes can be modernized, they make no attempt to identify the consequences of these approaches.

The recently published World Health Organization (WHO, 2016b) document focusing on the human resources for health strategy through 2030 clearly articulates the many and significant changes that health professionals of the future will face. Changing population demographics with increasing numbers of the very elderly, increased globalization and mobility of health workers and of individuals seeking treatment, raised public expectations, a rapid increase in noncommunicable diseases, and the emergence of new infectious diseases as well as the reemergence of old ones such as tuberculosis will all require new approaches to health care and its delivery. Technology will undoubtedly be integral to health care delivery in the future. As a result of such technology, existing jurisdictional boundaries will encounter unprecedented challenges as practitioners increasingly deliver borderless health care (Briggs, Foutty, \& Hodgetts, 2016).

Acknowledging the contributions and challenges discussed above is essential to understanding the evolution of regulation and the associated powers, processes, and responsibilities. However, the studies mentioned here by no means constitute a comprehensive review of the subject. To help guide the development of a contemporary approach to regulation, a systematic examination of the literature and an analysis of the potential implications of identified trends are required. A discussion of the bibliometric analysis performed as part of this study follows.

\section{Bibliometric Analysis}

A bibliometric approach to the analysis of the scientific literature regarding professional self-regulation and occupational licensure has rarely, if ever, been used to identify trends, and issues contained in the entire regulatory literature; the approach has been used, however, to map the emergence of domains of knowledge and their evolution over time in such areas as the study of technologies (Gerdsri, Kongthon, \& Vatananan, 2013). In relation to regulatory science, this approach has been used to analyze the content of a single journal (Benton \& Alexander, 2016) and in a study of scope of practice (Benton, Cusack, Jabbour, and Penney, 2017). The journal analysis offers insights into one journal's coverage of regulatory topics, their evolution over time, and the impact the content was exerting on scholarship in regulatory science. As for the study of scope of practice, only a subset of the regulatory literature was presented; therefore, only a partial view of change within the regulatory arena was explored (Benton et al., 2017). These studies are certainly valuable in offering a picture of the evolution of current regulatory science, but far more work needs to be done.

\section{Aim}

This study used a bibliometric analysis of the peer-reviewed literature of professional self-regulation and occupational licensure to identify overarching and developing trends in nursing regulation as the profession moves toward creating a regulatory model fit for the year 2030.

\section{Method}

The bibliometric technique of co-word and co-citation analysis of the peer-reviewed literature and an associated paper review of the identified "Professional Self-Regulation" OR "Occupational Licensure" materials are used to isolate individual trends in the evolution of nursing regulation.

\section{Data Sources and Structured Search}

A two-part structured search of a number of bibliographic databases, including PubMed, Scopus, and Web of Science, was conducted to identify papers that related to "Professional Self-Regulation" OR "Occupational Licensure" AND "Nursing" OR "Nurses" OR "Nurse." Part one of the search identified papers relating to professional self-regulation or occupational licensing. Part two extracted those papers identified from part one that related to nurses or nursing.

\section{Data storage}

Identified papers from both the part-one and part-two searches were saved as two RIS files (a standardized format developed by Research Information Systems). The files were then imported into Endnote $\mathrm{x} 7$ (Thompson Reuters) so duplicates could be identified and removed from each file. The cleaned files were then saved and made ready for importing into the bibliographic analysis software (VosViewer). VosViewer, a custom-designed software, enables researchers to conduct a range of bibliographic analyses (Van Eck \& Waltman, 2014), in this case, co-word analysis and co-citation analysis. 
Co-word analysis

Co-word analysis identifies nouns and noun clauses that appear in the title, abstract, or keywords of papers. Groups of co-words that appear in publications in similar patterns can be clustered together using a multidimensional scaling technique to generate groups of words that are individually and collectively examined to identify themes. To help identify the groups of words, the words may be color-coded. Consequently, researchers can identify the underlying structure of knowledge in a specific domain and, by examining this structure at different points in time, identify trends in the evolution of concepts. By looking at the most-cited work and the average date of publication of the source articles from which the co-words and trends are drawn, the relationship between trends and antecedent concepts can be identified (Bhattacharya \& Basu, 1998).

The density of the words and associated links (lines connecting the words) can be difficult to interpret. Accordingly, the number of links can be limited to help clarify the connections or can be removed altogether. The software allows the researcher to zoom into the map, which permits a more-detailed examination to facilitate scrutiny of the underlying structure (Van Eck \& Waltman, 2016). The researcher can zoom into a certain area and explore the clusters (the words of the same color), the links between words, the average date of publication of the papers from which the word has been identified, and the average citation frequency of the papers. Looking at the image in a detailed and granular form increases understanding of the underlying and evolving image.

Co-citation analysis

Co-citation analysis identifies the links between documents when a single document cites two other documents. If those two documents are cited frequently together, they are said to have a strong relationship with each other.

When many documents cite the same authors, clusters of research emerge and help reveal the underlying cognitive structure of the work. Chains of authors, such as those illustrated in Figure 1.1, can provide a means of exploring the progression of a concept over time.

\section{FIGURE 1.1}

\section{Co-citation analysis exploring the progression of regulatory research}

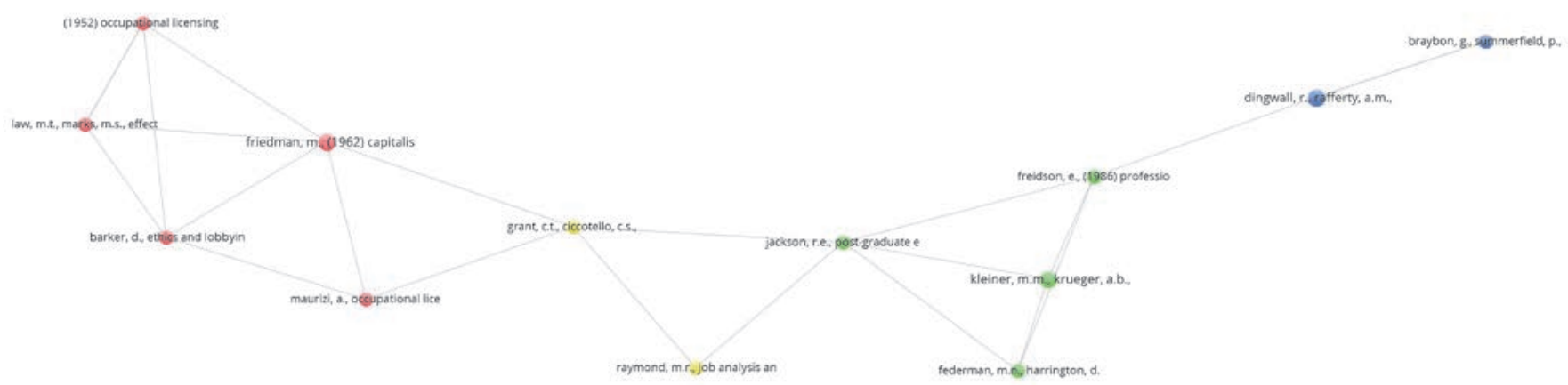

\section{Results}

A systematic analysis for "Professional Self-Regulation" OR "Occupational Licensure" of PubMed, Scopus, and the Web of Science, once duplicates had been removed, yielded a total of 2,976 articles. When this initial search was then limited to "Professional SelfRegulation" OR “Occupational Licensure” AND "Nurse” OR "Nurses" OR "Nursing”, 654 remained. Table 1.1 provides a summary of the yield from each source.

\section{TABLE 1.1}

\section{Summary of Article Yields From Respective Databases}

\begin{tabular}{lcccc}
\hline & PubMed & Scopus & Web of Science & Total with Duplicates Removed \\
\hline $\begin{array}{l}\text { "Professional Self-Regulation” OR “Occupational } \\
\text { Licensure" }\end{array}$ & 102 & 2,593 & 1,718 & 2,976 \\
\hline $\begin{array}{l}\text { "Professional Self-Regulation” OR “Occupational } \\
\text { Licensure" AND “Nurse” OR “Nurses” OR “Nursing” }\end{array}$ & 21 & 618 & 95 & 654 \\
\end{tabular}




\section{Documenting themes and trends}

As themes were identified, the literature associated with them was examined for evolving trends to be documented. A modified framework was used to document in a matrix format the evolution of the trends across early, consolidated, and early 21 st century time frames, and the consequent emergent trends of today. It was not possible to locate these trends to a specific date in time since regulation has been introduced and has evolved at a different pace across the various jurisdictions. Nonetheless, the stages of evolution should be thought of as progressive over time. In addition, themes are grouped under general category headings in order to locate like-with-like issues.

Twenty-five emergent trends were identified as a result of the bibliometric analysis. (See Table 1.2.) They can be clustered under seven major categories: Governance, Purpose and Processes, Licensees/Registrants, Workforce, Education, Fitness for Practice, and Technology and Education.

\section{Summary of Categories, Themes, Evolving Trends, and Emergent Trends \\ Governance category}

Four themes are classified under the category of Governance: nature of the regulator; character of the board; members of the regulatory board; and accountability.

\section{Nature of the regulator}

According to the literature on occupational licensing, the nature of the regulator can be traced back to trade guilds; indeed, some authors contend that some regulators continue to pursue professional interest rather than one that protects the public (Kleiner \& Krueger, 2008). From these guilds emerged self-regulatory bodies that focused on a specific discipline and were granted their authority under statute. Recently, these independent bodies have, in some cases, been brought together under umbrella arrangements, in which the degree of autonomy of any one discipline has frequently been delimited. It has been argued, often in the absence of any evidence, that such arrangements are more efficient and effective (Rachlis \& Kushner, 1994). However, existing evidence points toward the independent board structure as being more efficient and effective (Benton, Brekken, Ridenour, \& Thomas, 2016; Maggetti, 2010). Indeed, in the wider regulatory literature, the $\operatorname{OECD}(2016,2017)$ has argued strongly for greater independence. Irrespective of the organizational accountabilities, regulatory boards today are increasingly held to account via performance measures that entail systematic and frequent reviews frequently accompanied by some form of independent oversight.

\section{Character of the board}

Over time, the character of the board has changed. Initially, boards were composed of self-appointed elite members of the profession, with no lay representation. For many years, the composition of boards focused on elected representatives who were drawn from different parts or levels of the profession. As thinking evolved, the focus moved toward achieving excellence in specific aspects of the board's work, for example, discipline, educational standards, and accreditation. However, after major governance failures across a wide range of industries in the late 1990s and the first decade of the 21st century, boards are now more focused as corporate accountable entities that are expected to act in transparent and accountable ways and include lay members among their membership (Minnesota Council of Nonprofits, 2014; OECD, 2014).

\section{Members of the regulatory board}

Linked to the previous trend, the members of the regulatory board have changed from self-appointed individual members of the profession to elected members of the profession, to appointed individuals who are frequently nominated by the profession but whose position is endorsed by the governor or minister. More recently, however, and in step with the governance changes detailed above, potential board candidates are assessed for their competence and then appointed through impartial processes such as those followed by the Centre for Public Appointments of the United Kingdom (https://publicappointments.cabinetoffice.gov.uk/about-appointments/) that appoints members to the Nursing and Midwifery Council.

Accountability

Just as other aspects of governance have changed, so too has the accountability of the board. Initially, boards were accountable to the profession, but over time, and as the demand for more public accountability increased, governors and ministers have played an increasing role. More recently, however, there has been an increase in the number of boards that have some form of external, independent oversight committee that monitors and reviews the actions of boards and challenges a board's decisions when the oversight committee believes that the board has failed to comply with their statutory duties. The Professional Standards Authority in the United Kingdom is one example of this type of oversight model. The ways in which boards are held to account can vary considerably and can be influenced by the legal tradition of the country as well as other factors (Benton, Fernández-Fernández, González-Jurado, \& Beneit-Montesinos, 2015). Recently, changes resulting from the U.S. Supreme Court decision in North Carolina Board of Dental Examiners v. Federal Trade Commission have resulted in even more diversity in how boards in the United States are held to account. 


\section{TABLE 1.2}

\section{Identifying the Evolution of Regulatory Trends over time}

The evolution of regulatory trends identified in the literature across early, consolidated, and early 21 st century time frames, and the consequent emergent trends are presented here and are grouped under general category headings.

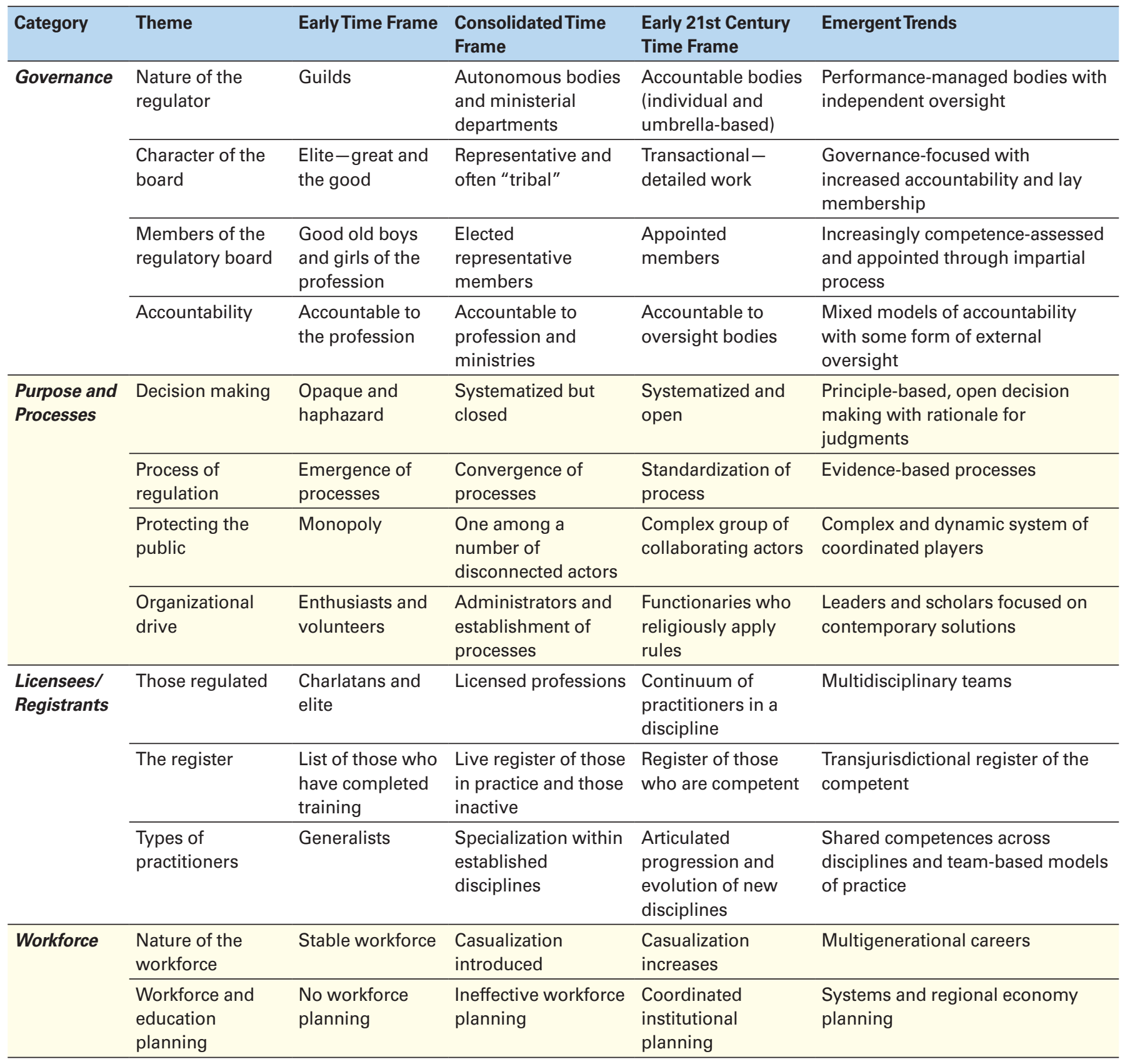




\section{Identifying the Evolution of Regulatory Trends over time (continued)}

\begin{tabular}{|c|c|c|c|c|c|}
\hline Category & Theme & Early Time Frame & $\begin{array}{l}\text { Consolidated Time } \\
\text { Frame }\end{array}$ & $\begin{array}{l}\text { Early 21st Century } \\
\text { Time Frame }\end{array}$ & Emergent Trends \\
\hline \multirow[t]{3}{*}{ Education } & Setting standards & $\begin{array}{l}\text { Based on } \\
\text { education and } \\
\text { training }\end{array}$ & $\begin{array}{l}\text { Formal standards of } \\
\text { content (knowledge), } \\
\text { codes of conduct }\end{array}$ & $\begin{array}{l}\text { Based on } \\
\text { competencies and } \\
\text { tasks }\end{array}$ & $\begin{array}{l}\text { Higher-level competencies relating } \\
\text { to judgment and decision making }\end{array}$ \\
\hline & $\begin{array}{l}\text { Curriculum } \\
\text { content }\end{array}$ & $\begin{array}{l}\text { Variations of } \\
\text { curriculum } \\
\text { across schools }\end{array}$ & $\begin{array}{l}\text { Variation of } \\
\text { curriculum across } \\
\text { countries }\end{array}$ & $\begin{array}{l}\text { Variation based on } \\
\text { health needs }\end{array}$ & $\begin{array}{l}\text { Global calibration of differences } \\
\text { and harmonization of content }\end{array}$ \\
\hline & Learning & Once and for all & $\begin{array}{l}\text { Once and for all + } \\
\text { additional topic- } \\
\text { based courses }\end{array}$ & $\begin{array}{l}\text { Lifelong learning } \\
\text { and continuing } \\
\text { education }\end{array}$ & $\begin{array}{l}\text { Continuing and maintaining } \\
\text { competence }\end{array}$ \\
\hline \multirow[t]{3}{*}{$\begin{array}{l}\text { Fitness for } \\
\text { Practice }\end{array}$} & Fit person & Not considered & Self-declared & $\begin{array}{l}\text { Self-declared with } \\
\text { sign-off by } \\
\text { responsible other }\end{array}$ & $\begin{array}{l}\text { Ongoing process with criminal } \\
\text { background checks and rapback }\end{array}$ \\
\hline & $\begin{array}{l}\text { Dealing with } \\
\text { complaints }\end{array}$ & $\begin{array}{l}\text { Judged by peers } \\
\text { in secret }\end{array}$ & $\begin{array}{l}\text { Judged by peers } \\
\text { with formal reporting }\end{array}$ & $\begin{array}{l}\text { Judged by mix of } \\
\text { peers and lay } \\
\text { members }\end{array}$ & $\begin{array}{l}\text { Clear separation of investigation, } \\
\text { judgment, and outcome }\end{array}$ \\
\hline & Conduct sanctions & $\begin{array}{l}\text { Poor conduct } \\
\text { ignored }\end{array}$ & Rigid rules applied & $\begin{array}{l}\text { Separation of } \\
\text { health, conduct, and } \\
\text { competence issues }\end{array}$ & $\begin{array}{l}\text { Risk-based response and wider } \\
\text { range of sanctions }\end{array}$ \\
\hline \multirow{2}{*}{$\begin{array}{l}\text { Technology } \\
\text { and } \\
\text { Information }\end{array}$} & Data access & No access & $\begin{array}{l}\text { Physical access of } \\
\text { registers by visiting } \\
\text { the board or reading } \\
\text { the once-a-year } \\
\text { published list of } \\
\text { registrants }\end{array}$ & Web-based access & $\begin{array}{l}\text { Real time updates and } \\
\text { multiplatform access }\end{array}$ \\
\hline & Relicensure & Did not exist & $\begin{array}{l}\text { Three- to five-year } \\
\text { cycle of postal-based } \\
\text { completion and } \\
\text { return }\end{array}$ & $\begin{array}{l}\text { Annual process } \\
\text { using Web } \\
\text { technology and } \\
\text { direct debit } \\
\text { payments }\end{array}$ & $\begin{array}{l}\text { Smart phone completion platforms } \\
\text { with digital payment }\end{array}$ \\
\hline
\end{tabular}

\section{Purpose and Processes category}

Four themes are classified under the category of Purpose and Processes: decision making; process of regulation; protecting the public; and organizational drive.

\section{Decision making}

Decision making has changed significantly over the years, from a model that was cloaked in mystery to one that that has been increasingly systematized and is now moving toward a set of agreed principles. This shift has resulted in more reliable and consistent decision mak- 
ing that is open to scrutiny and increasingly accompanied by a sound rationale that is aligned with a set of core principles that support the judgments being proffered (Public Sector Commission, 2016).

\section{Process of regulation}

As jurisdictions have gained in experience, they have developed and evolved their process of regulation. Increased globalization and a stronger connection between regulators have encouraged sharing of best practices (International Council of Nurses [ICN], 2009). In addition, the emphasis on the generation and application of research has increased (Benton \& Alexander, 2016). Growth in these areas has resulted in a convergence and standardization of approaches that are now rapidly moving toward the realization of evidence-based regulation.

\section{Protecting the public}

Protecting the public has moved from a situation in which the regulator was an isolated and unique entity focused on a single discipline and a monopoly advocate for public protection to an interactive network of players who operate in a codependent, complex, and dynamic system - a system in which the regulator is but one part of a range of approaches that collectively contribute to public safety.

\section{Organizational drive}

The initial regulatory organizational drive was propelled by enthusiasts and volunteers, but such are the challenges facing regulators today that regulatory bodies are being driven forward by highly accomplished and educated leaders and scholars who seek contemporary solutions in order to keep pace with the increasing needs of citizens and the aspirations of government. Recently, global policy documents have placed the need to reform regulation and the demand for contemporary solutions on center stage (WHO, 2016a, 2016b).

\section{Licensees/Registrants category}

Three themes are classified under the category of Licensees/Registrants: those regulated; the register; and types of practitioners.

\section{Those regulated}

Over time, the focus of those regulated has shifted from charlatans and the elite, to licensed professionals, to the continuum of practice associated with a particular discipline, to an emergent discussion on how interdisciplinary teams might be regulated. This set of trends arose from the early realization of the threats that charlatans presented to the public and the desires of the discipline's elite to create mechanisms to protect the public and professionalize the discipline (Krause, 1996). The focus then shifted to the definition of the individual licensees. In some cases, this resulted in different regulatory boards for the different levels of practitioner. Although boards that deal exclusively with practical nurses, registered nurses, and advanced practice nurses still exist, the tendency has been for these boards to merge into entities that cover the entire continuum of a discipline's practice; that is, a shift away from looking at the individual nurse to a broader perspective of looking at the entirety of nursing practice. Recently, owing to the realization that health care is becoming more complex and that the manner in which care is delivered relates to multidisciplinary teams, questions on how such teams may be regulated are starting to emerge (The American College of Obstetricians and Gynecologists, 2016).

\section{The register}

The register started as a simple list of those who had completed an approved training. Over time, it has become more sophisticated, differentiating those who remain in active practice from those who are no longer working in the profession. However, the increasing pace of health care change has demonstrated a need for practitioners to maintain their competence. Because of globalization and increased mobility across jurisdictions, there has been an impetus to develop systems that support a transjurisdictional register of the competent. Such support systems strike a balance between protecting the public and facilitating nurse mobility.

\section{Types of practitioner}

As health care delivery has become more complex, so too have the roles and types of practitioner. Initially, generalists were the norm; however, over time roles were differentiated by level of practitioner, setting, disease type, and treatment modalities. Nearly a decade ago the focus was on the continuum of practice (ICN, 2008). This focus led to the concept of identifying competencies that became more complex as the practitioner moved from support role, to practical nurse, to registered nurse, to advanced practice. In addition to vertical progression and linked to the concepts of team-based care, shared competencies across disciplines are now being identified.

\section{Workforce category}

Two themes are classified under the category of Workforce: nature of the workforce and workforce and education planning.

\section{Nature of the workforce}

In most countries, nursing at the onset of the profession was a female-dominated career. The nature of the workforce was stable: Students typically entered the profession straight from school and, once qualified, worked full time. As population demographics have shifted and concepts such as flexible working practices have been introduced along with other developments (such as nursing agencies and 
travel nursing), there has been a casualization of the workforce, which is further complicated by the multigenerational nature of today's workforce. Individuals may enter the profession as a second or subsequent career, do not see the profession as a job for life, or are more interested in striking a sound life-work balance.

\section{Workforce and educational planning}

With the increased complexity of the workforce, the need for workforce and educational planning has also increased. Initially, regulators did not have a role in workforce planning; even as the need for such planning was recognized, the planning was frequently fragmented and incomplete. The WHO (2016b) world health report highlights the need to improve workforce and educational planning if peaks and troughs, both across and between jurisdictions, were to be avoided. The WHO report has triggered more comprehensive and coordinated planning, first at institutional levels, and more recently as part of national and regional economies. Regulators have been increasingly invited to participate in such dialogue, as their live registers contribute valuable human resources for health data.

\section{Education category}

Five themes are classified under the category of Education: setting standards; curriculum content; accreditation of institutions and programs; learning; and pedagogy.

\section{Setting standards}

The process of setting standards has evolved over the years and has accompanied a transition from a model of training based on the apprentice model to one based on a partnership between service and education. In many parts of the world, the standard-setting process is moving from a model focused on knowledge and skill content to one based on competence. As health care knowledge grows, this model of competence also needs to grow, with an even greater focus on higher-level competencies specifically related to judgment and decision making (Dickison et al., 2016).

\section{Curriculum content}

Initially, curriculum content varied from school to school. As regulatory bodies developed and implemented their standards and associated accreditation processes, curriculum content became more uniform within jurisdictions. As knowledge of health needs increases, regulators are tasked with ensuring that curriculum content includes material relevant to jurisdictions' population health needs; as a result, variation from one jurisdiction/country to another does occur. However, with increased mobility, the need to globally calibrate these differences has increased. By calibrating the differences, gaps that may occur as a practitioner moves from one jurisdiction to another can be identified and addressed. Furthermore, events such as the Ebola outbreak and its subsequent spread to different parts of the world have highlighted the need to harmonize curricula whenever possible to enable the deployment of additional practitioners to hot spots when necessary.

\section{Accreditation of institutions and programs}

Initially, the regulator was not involved in the accreditation of institutions and programs, but as the need to standardize and ensure the competence of those entering the register increased, stand-alone accreditation by the regulator was introduced. As nursing education moved into the higher education sector, a degree of overlap between the processes of the regulators and educational institutional accreditors appeared. These parallel systems frequently resulted in the same information being requested and collected more than once, albeit in different formats, demonstrating the need to capture data once and then use it many times in order to pursue a more effective, efficient, valid, and reliable approach.

Learning

Since the inception of regulatory boards, the level of knowledge has risen dramatically, indicating that the nature of learning had to change. There was a time when education and learning occurred at the start of a career. However, as nursing knowledge expanded and treatment options increased so did the need for additional top-up courses. As the years passed, it became obvious that a shift in the philosophy of learning was needed-from a philosophy of once in a lifetime to one of lifelong learning and continuing education. More recently, nurse educators have come to realize that education is insufficient if competence cannot be maintained; therefore, regulatory bodies now need to develop systems that pursue and ensure continuing competence.

\section{Pedagogy}

Major changes have taken place in relation to pedagogy. Indeed, it is fair to say that the model has moved from a pedagogic model to an andragogic model. Initially, an approach where the learner was dependent on the teacher, where the learner was told what to do and pursued a period of apprenticeship was the norm. Since those early days, a series of educational reforms encouraged self-directed adult learning, and technological advances now play a central role. Technology and new learning modalities help learners equip themselves with the necessary competence to pursue lifelong learning. Blended learning and problem-based scenarios facilitate attainment of the necessary competencies from peer interaction as much as from teacher direction. 


\section{Fitness for practice category}

Four themes are classified under the category of Fitness for Practice: fit person; dealing with complaints; conduct sanctions; and entry to practice,

\section{Fitperson}

Although regulation from the onset has sought to protect the public, formal consideration of the individual practitioner's fitness to practice on an ongoing and formal basis is a relatively recent development. It is only in the past several decades that progressively more stringent mechanisms have been used. These mechanisms have evolved from a self-declaration with no oversight to an approach where a peer or supervisor has to co-sign the declaration. More recently, however, in addition to the self-declaration and peer sign-off, dynamic systems that utilize criminal background checks have been introduced.

\section{Dealing with complaints}

Over the years, the manner in which regulatory bodies have dealt with complaints has become increasingly transparent and structured. Early processes used a closed system that included judgment by peers and limited reporting. Subsequently, this system was replaced by one that required formal reporting of findings, with the involvement of lay panel members. Presently, the complaints process consists of a clear separation of investigative procedures, judgment of the case, and determination of board actions. Statements of fact and rationale for the actions taken are becoming more readily accessible to the public.

\section{Conduct sanctions}

The range of conduct sanctions has gradually increased. Initially, poor conduct, unless extreme, was frequently ignored; however, as the complaint process became more transparent, a narrow set of sanctions was introduced and rigidly applied. But as regulatory bodies gained more experience, the need to separate individuals with health problems from those who presented with conduct or competency issues became clear. This differentiation of the root cause of the underlying problem is still advancing, with the introduction of a risk-based approach in which a much wider range of sanctions, supervision, restriction on practice, retraining, and other remediation strategies have been introduced.

\section{Entry to practice}

At the onset of nursing regulation, entry to practice was based on the completion of an apprenticeship. As the number of nursing programs increased and it was acknowledged that the practice of nursing was both an art and a science, final written exams were introduced that were held once or twice a year and required the candidate to complete a number of essay-type questions. More recently, candidates have had to complete an approved program of study with ongoing formative assessment and frequently a summative multiple-choice examination that, in some cases, utilizes computer adaptive testing. The increasing complexity of health care has created the need to test the application of knowledge through standardized adaptive exams in order to assess judgment and decision making.

\section{Technology and information category}

Three themes are classified under the category of Technology and Information: data production and storage; data access; and relicensure.

\section{Data production and storage}

When regulatory bodies first appeared, data production and storage involved the use of pens and written ledgers. Once an individual had completed the approved training, the individual's name was entered into a ledger - the register. The register was extremely difficult to access and could only be viewed physically in the board of nursing's office. Over time, wider distribution of such information was possible, often via the inclusion of the information in the printed record of government publications such as the official gazette. As technology evolved, such information was stored digitally, but these storage systems frequently had very limited interoperability and poor query functions. Today, an increasing number of regulatory bodies use cloud-based computer storage and databases that can be accessed from anywhere in the world, 24 hours a day, with dynamic search capability and intelligent display capabilities that enable the information to be adapted to any digital device format, such as smart phone, iPad, laptop, or desktop computer.

\section{Data access}

As already noted, data access has increased from relatively no access, to physical access, to various forms of digital systems. Today, realtime updates can be sent to a registrant when a license is due for renewal and to employers when the status of any license changes. Data access has therefore moved from a reactive system to one that is increasingly proactive in communicating to interested parties any required information.

\section{Relicensure}

For many years, relicensure was not a requirement and licenses, once issued, were for life. Indeed, many registers until quite recently contained the names of individuals who were deceased. To obtain more accurate registers, licensure renewal was introduced, usually on 
a 5-year or more-frequent basis. This process required the completion of paper-based documents that had to be presented or returned by post to the regulatory body. Technology has streamlined this process; as a result, there are now Web-based systems with direct debit payment, and smart phone completion and digital payment platforms are becoming more common.

\section{Limitations}

Since the co-word analysis is based on an examination of title, abstracts, and keywords rather than on the content of entire papers, it is possible that some trends have been missed. To address this problem, expert participants in Step Two of this study were asked to comment on the 25 identified emergent trends and to augment them should they feel that one or more are missing or their characteristics lack precision. It must also be noted that some grey literature relating to professional self-regulation and occupational licensure may have been omitted from the analysis. Again, expert review of the matrix in Step Two would help address this potential limitation.

\section{Conclusion}

Twenty-five emergent trends that were allocated to seven major categories have been identified and discussed. Each of the 25 themes has progressed over time; emergent thinking or action stands at the leading edge of these emergent trends that will lead ultimately to further change. The challenge is to understand these emergent trends and to identify how they might be accelerated should they offer improvements in public protection or be halted or redirected should they offer less efficient and effective regulatory systems. This discussion continues in Steps Two and Three of the Regulation 2030 study, which follow here. 